\title{
Pregnancy-triggered atypical hemolytic uremic syndrome (aHUS): a Global aHUS Registry analysis
}

\author{
Fadi Fakhouri $^{1} \cdot$ Marie Scully ${ }^{2} \cdot$ Gianluigi Ardissino $^{3} \cdot$ Imad Al-Dakkak $^{4} \cdot$ Benjamin Miller $^{4} \cdot$ Eric Rondeau $^{5}$
}

Received: 8 December 2020 / Accepted: 10 March 2021 / Published online: 7 April 2021

(c) The Author(s) 2021

\begin{abstract}
Background Atypical hemolytic uremic syndrome (aHUS) is a rare disease in which uncontrolled terminal complement activation leads to systemic thrombotic microangiopathy (TMA). Pregnancy can trigger aHUS and, without complement inhibition, many women with pregnancy-triggered aHUS (p-aHUS) progress to end-stage renal disease (ESRD) with a high risk of morbidity. Owing to relatively small patient numbers, published characterizations of p-aHUS have been limited, thus the Global aHUS Registry (NCT01522183, April 2012) provides a unique opportunity to analyze data from a large single cohort of women with p-aHUS.

Methods The demographics and clinical characteristics of women with p-aHUS $(n=51)$ were compared with those of women of childbearing age with aHUS and no identified trigger (non-p-aHUS, $n=397$ ). Outcome evaluations, including renal survival according to time to ESRD, were compared for patients with and without eculizumab treatment (a complement C5 inhibitor) in both aHUS groups.

Results Baseline demographics and clinical characteristics were broadly similar in both groups. The proportion of women with p-aHUS and non-p-aHUS with pathogenic variant(s) in complement genes and/or anti-complement factor $\mathrm{H}$ antibodies was similar (45\% and 43\%, respectively), as was the proportion with a family history of aHUS (12\% and 13\%, respectively). Eculizumab treatment led to significantly improved renal outcomes in women with aHUS, regardless of whether aHUS was triggered by pregnancy or not: adjusted hazard ratio for time to ESRD was $0.06(p=0.006)$ in the $\mathrm{p}$-aHUS group and 0.20 $(p<0.0001)$ in the non-p-aHUS group.
\end{abstract}

Conclusion Findings from this study support the characterization of p-aHUS as a complement-mediated TMA.

At the time of this study, Benjamin Miller was an employee of Alexion Pharmaceuticals, Inc., Boston, MA, USA.

Fadi Fakhouri

fadi.fakhouri@unil.ch

1 Service of Nephrology and Hypertension, University of Lausanne, Lausanne, Switzerland

2 University College London, London, UK

3 Center for HUS Control, Prevention and Management, Milan, Italy

4 Alexion Pharmaceuticals, Inc., Boston, MA, USA

5 Present Address: Hôpital Tenon, Paris, France 


\section{Graphic abstract}

\section{Pregnancy-triggered atypical hemolytic uremic syndrome (aHUS): a Global aHUS Registry analysis}

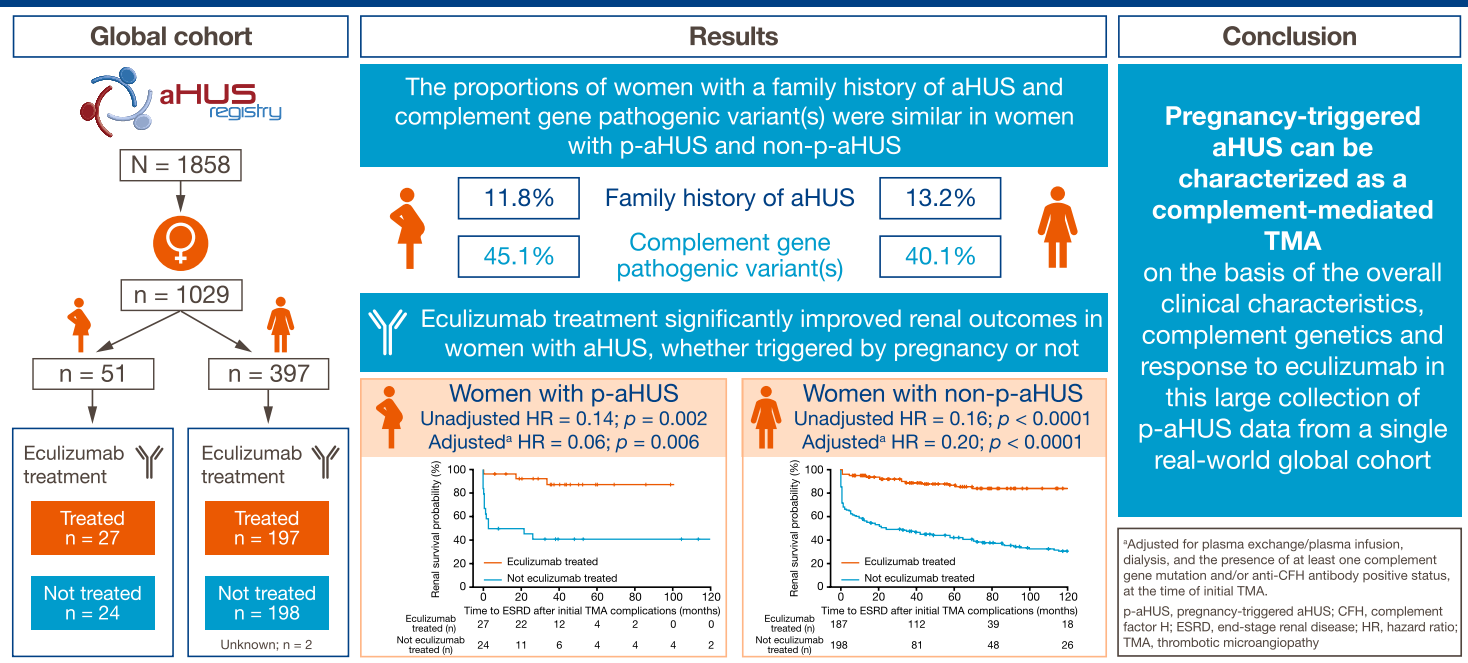

Keywords Atypical hemolytic uremic syndrome (aHUS) - Complement-mediated TMA · Complement C5 inhibitor · Endstage renal disease (ESRD) · Pregnancy

\section{Introduction}

Atypical hemolytic uremic syndrome (aHUS) is a rare disease caused by dysregulation of the alternative pathway of complement. The resulting uncontrolled terminal complement activation causes inflammation, endothelial activation and damage, and a pro-thrombotic/pro-anticoagulant state leading to systemic thrombotic microangiopathy (TMA) [1-3]. Patients with aHUS are at risk of unpredictable and/or progressive TMA-mediated damage to renal and other organ systems, leading to severe morbidity and premature death [4-6]. Identified triggers of aHUS include pregnancy, infection, autoimmune conditions, organ transplants, and certain drug treatments [7-9].

Pregnancy-triggered aHUS (p-aHUS) presents during pregnancy or postpartum and has been estimated to account for approximately $7 \%$ of all cases with aHUS and up to $20 \%$ of cases in women $[5,10]$. In a 2019 retrospective study of a French cohort with adjudicated TMAs, Bayer et al. reported that among patients with identified causes of TMA, pregnancy was the leading cause of secondary TMA (35\%) [9]. p-aHUS is associated with high perinatal or maternal morbidity and mortality, with many women progressing to end-stage renal disease (ESRD) [7, $10,11]$.

Without targeted treatment, outcomes of patients with aHUS are poor. Despite the use of plasma exchange (PE) or plasma infusion (PI), more than half of patients progress to ESRD or death [4-6]. The terminal complement $\mathrm{C} 5$ inhibitors, eculizumab and ravulizumab, are targeted treatments approved for patients with aHUS [12-15]. The efficacy and safety of eculizumab (first approved in 2011) in the treatment of aHUS has been demonstrated in four prospective clinical trials and has been supported by additional data from registries and other real-world patient studies [16-22].

Given the rarity of aHUS, the Global aHUS Registry provides a unique opportunity to characterize the disease further, using data from multiple participating centers worldwide. The objective of this study was to use Global aHUS Registry data to compare the clinical characteristics and renal outcomes, with and without eculizumab treatment, in women with p-aHUS with those in women of childbearing age with aHUS but without identified triggers.

\section{Methods}

Patients with a clinical diagnosis of aHUS were included in the observational non-interventional Global aHUS Registry (NCT01522183) [23]. This registry was initiated in April 2012 to evaluate the clinical outcomes of patients with aHUS irrespective of the treatment modality used [24]. The registry study was established in accordance 
with the International Conference on Harmonisation Good Clinical Practice Guidelines and the Declaration of Helsinki. All patients provided written Informed Consent before participation.

Patients meeting the registry inclusion criteria were males or females of any age with a diagnosis of aHUS, with or without an identified complement pathogenic variant or anticomplement factor $\mathrm{H}(\mathrm{CFH})$ antibody [24]. Patients with evidence of Shiga toxin-producing Escherichia coli infection and those with a disintegrin and metalloproteinase with a thrombospondin type 1 motif-13 (ADAMTS13) activity level of 5\% or lower (the level consistent with a diagnosis of thrombotic thrombocytopenia purpura), if performed, were excluded [24].

In this analysis, patients with p-aHUS were identified in the Global aHUS Registry as female patients with first TMA manifestations/complications during pregnancy or within 60 days postpartum. Only women with at least 90 days of follow-up after initial TMA manifestations/complications were included. Women were excluded if they had any other identified trigger of aHUS (history of drug-induced aHUS; first onset of symptoms within 14 days of Streptococcus pneumoniae infection; first onset of symptoms within 1 year of a bone marrow transplant; or coexisting autoimmune conditions identified by the treating physician [no further details recorded], at the time of initial TMA complications/manifestation) or if they discontinued the registry or eculizumab treatment owing to an alternative diagnosis. A comparator group of women with aHUS not triggered by pregnancy (non-p-aHUS), was comprised of female patients in the Global aHUS Registry of childbearing age (18-51 years), with at least 90 days of follow-up after initial TMA manifestations/complications and no other identified trigger of aHUS or alternative diagnosis (as described in the exclusion criteria above).

Descriptive statistics were used to identify similarities and differences between the p-aHUS and non-p-aHUS groups in terms of baseline demographics and clinical characteristics, including treatments received. Women in each group were stratified into those treated with eculizumab (at least one dose; 600,900 or $1200 \mathrm{mg}$ ) and those not treated with eculizumab, the latter including those never treated with eculizumab as well as those who did not receive eculizumab prior to ESRD. Cox regression was used to compare renal prognoses between aHUS groups and between women treated and not treated with eculizumab. The hazard ratio

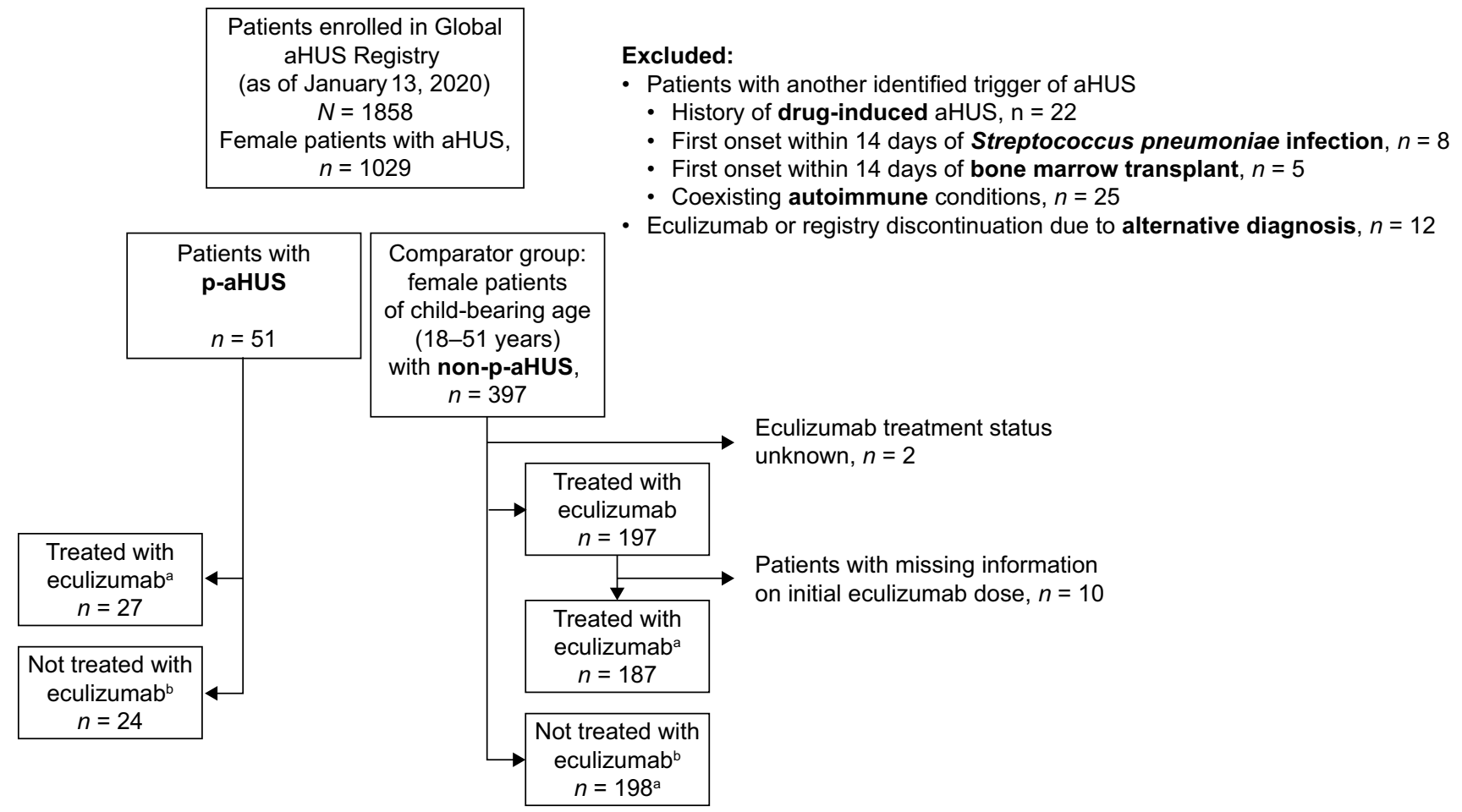

Fig. 1 Study of women with aHUS of childbearing age in the Global

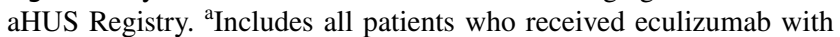
initial TMA complications. ${ }^{b}$ Includes patients never treated with ecu- lizumab and those who did not receive eculizumab prior to end stage renal disease. aHUS atypical hemolytic uremic syndrome, $p$-aHUS pregnancy-triggered aHUS 
Table 1 Baseline demographics and clinical characteristics of women with p-aHUS and non-p-aHUS

\begin{tabular}{|c|c|c|c|c|c|c|}
\hline & \multicolumn{3}{|c|}{ Women with p-aHUS $(n=51)$} & \multicolumn{3}{|c|}{ Women with non-p-aHUS $(n=395)^{\mathrm{a}}$} \\
\hline & $\begin{array}{l}\text { Eculizumab treated } \\
(n=27)\end{array}$ & $\begin{array}{l}\text { Not treated } \\
\text { with eculi- } \\
\text { zumab } \\
(n=24)\end{array}$ & $\begin{array}{l}\text { All patients } \\
(n=51)\end{array}$ & $\begin{array}{l}\text { Eculizumab treated } \\
(n=187)\end{array}$ & $\begin{array}{l}\text { Not treated } \\
\text { with eculi- } \\
\text { zumab } \\
(n=198)\end{array}$ & $\begin{array}{l}\text { All patients } \\
(n=395)\end{array}$ \\
\hline $\begin{array}{l}\text { Age at aHUS diagnosis, years, mean } \\
\text { (SD) }\end{array}$ & $30.8(5.5)$ & $31.7(6.3)$ & $31.2(5.9)$ & $30.4(11.0)$ & $27.5(10.8)^{\mathrm{b}}$ & $29.1(11.0)^{\mathrm{c}}$ \\
\hline \multicolumn{7}{|l|}{ Family history of aHUS, $n(\%)$} \\
\hline Yes & $3(11.1)$ & $3(12.5)$ & $6(11.8)$ & $23(12.3)$ & $29(14.6)^{b}$ & $52(13.2)^{\mathrm{c}}$ \\
\hline No & $22(81.5)$ & $17(70.8)$ & $39(76.5)$ & $141(75.4)$ & $140(70.7)^{\mathrm{b}}$ & $289(73.2)^{\mathrm{c}}$ \\
\hline Missing & $2(7.4)$ & $4(16.7)$ & $6(11.8)$ & $23(12.3)$ & $29(14.6)^{b}$ & $54(13.7)^{\mathrm{c}}$ \\
\hline \multicolumn{7}{|l|}{ Previous pregnancies, $n(\%)^{\mathrm{d}}$} \\
\hline Yes & $1(3.7)$ & 0 & $1(2.0)$ & $13(7.0)$ & $19(9.6)$ & $33(8.4)$ \\
\hline Prior to initial TMA & $1(3.7)$ & 0 & $1(2.0)$ & $5(2.7)$ & $12(6.1)$ & $18(4.6)$ \\
\hline After initial TMA & 0 & 0 & 0 & $9(4.8)$ & $8(4.0)$ & $17(4.3)$ \\
\hline No & $26(96.3)$ & $24(100.0)$ & $50(98.0)$ & $174(93.0)$ & $179(90.4)$ & $362(91.6)$ \\
\hline Initial TMA during pregnancy ${ }^{\mathrm{e}}, n(\%)$ & $12(44.4)$ & $16(66.7)$ & $28(54.9)$ & - & - & - \\
\hline $0-12$ weeks gestation & $3(11.1)$ & $9(37.5)$ & $12(23.5)$ & - & - & - \\
\hline 13-24 weeks gestation & $2(7.4)$ & 0 & $2(3.9)$ & - & - & - \\
\hline$>24$ weeks gestation & $7(25.9)$ & $7(29.2)$ & $14(27.5)$ & - & - & - \\
\hline $\begin{array}{l}\text { Initial TMA postpartum }(<60 \text { days } \\
\text { after pregnancy end date), } n(\%)\end{array}$ & $15(55.6)$ & $8(33.3)$ & $23(45.1)$ & - & - & - \\
\hline $\begin{array}{l}\text { Time from initial TMA to aHUS diag- } \\
\text { nosis, months, mean (SD) }\end{array}$ & $0.4(0.9)$ & $0.7(1.8)$ & $0.5(1.4)$ & $0.9(28.4)$ & $8.1(50.2)$ & $4.5(40.6)$ \\
\hline $\begin{array}{l}\text { Patients with kidney transplant prior to } \\
\text { index pregnancy, } n(\%)\end{array}$ & 0 & 0 & 0 & $21(11.2)^{\mathrm{f}}$ & $13(6.6)^{\mathrm{f}}$ & $34(8.6)^{\mathrm{f}}$ \\
\hline $\begin{array}{l}\text { Patients with kidney transplant after } \\
\text { index pregnancy, } n(\%)\end{array}$ & $2(7.4)$ & $10(41.7)$ & $12(23.5)$ & $15(8.0)^{\mathrm{g}}$ & $98(49.5)^{\mathrm{g}}$ & $113(28.6)^{\mathrm{g}}$ \\
\hline $\begin{array}{l}\text { Patients with ongoing dialysis at time } \\
\text { of initial TMA, } n(\%)\end{array}$ & $4(14.8)$ & $3(12.5)$ & $7(13.7)$ & $25(13.4)$ & $19(9.6)$ & $44(11.1)$ \\
\hline Patients with PE/PI anytime, $n(\%)$ & $22(81.5)$ & $18(75.0)$ & $40(78.4)$ & $131(70.1)$ & $146(73.7)$ & $280(70.9)$ \\
\hline Duration, days, mean (SD) & $13.2(16.1)$ & $20.9(23.4)$ & $16.7(19.9)$ & $41.16(154.5)$ & $211.8(713.1)$ & $129.8(531.8)$ \\
\hline $\begin{array}{l}\text { Patients with PE/PI prior to eculi- } \\
\text { zumab, } n(\%)\end{array}$ & $22(81.5)$ & - & - & $125(66.8)$ & - & - \\
\hline \multicolumn{7}{|l|}{$\begin{array}{l}\text { Patients with extra-renal manifesta- } \\
\text { tions associated with aHUS at time } \\
\text { of index TMA, } n(\%)\end{array}$} \\
\hline Cardiovascular & $5(18.5)$ & $2(8.3)$ & $7(13.7)$ & $33(17.6)$ & $14(7.1)$ & $49(12.3)$ \\
\hline Pulmonary & $4(14.8)$ & $1(4.2)$ & $5(9.8)$ & $19(10.2)$ & $9(4.5)$ & $28(7.1)$ \\
\hline $\mathrm{CNS}$ & $6(22.2)$ & $3(12.5)$ & $9(17.6)$ & $33(17.6)$ & $14(7.1)$ & $49(12.3)$ \\
\hline Gastrointestinal & $9(33.3)$ & 0 & $9(17.6)$ & $55(29.4)$ & $15(7.6)$ & 74 (18.6) \\
\hline
\end{tabular}

aHUS atypical hemolytic uremic syndrome, $C N S$ central nervous system, $p$ - $a H U S$ pregnancy-triggered aHUS, $P E / P I$ plasma exchange or plasma infusion, $S D$ standard deviation, TMA thrombotic microangiopathy

${ }^{\text {a Includes }} 10$ women with missing information on initial eculizumab dose

${ }^{\mathrm{b}} n=197$

${ }^{\mathrm{c}} n=394$

${ }^{\mathrm{d}}$ Number of pregnancies prior to or after index TMA for women with p-aHUS; number of pregnancies prior to enrollment or while enrolled for women with non-p-aHUS

${ }^{\mathrm{e}}$ Trimester information was only collected for 28/51 women, therefore it is difficult to make any inferences

f Transplantation prior to aHUS

${ }^{\mathrm{g}}$ Transplantation after aHUS 
(HR) based on time to ESRD after initial TMA manifestation was calculated to compare outcomes for patients with and without eculizumab treatment. The unadjusted HR was calculated as the risk of ESRD in women treated with eculizumab divided by the risk of ESRD in those not treated with eculizumab. In addition, HRs adjusted for the following covariates were calculated: (1) dialysis and/or PE/PI treatment, and (2) at least one complement gene mutation and/ or anti-CFH antibody positive status, at the time of initial TMA.

\section{Results}

\section{Study population}

As of January 13, 2020, 1858 patients were enrolled in the Global aHUS Registry, including 1029 female patients. For this study, 51 and 397 women of childbearing age were identified with p-aHUS or non-p-aHUS, respectively, after specific inclusion and exclusion criteria were applied. The groups used for comparative analyses are shown in Fig. 1.

\section{Baseline demographics and clinical characteristics}

Age at aHUS diagnosis was similar for women with p-aHUS and non-p-aHUS (mean \pm standard deviation [SD] $31.2 \pm 5.9$ years and $29.1 \pm 11.0$ years, respectively) and across treatment subgroups (Table 1). The mean time from initial TMA manifestation to aHUS diagnosis was shorter in the p-aHUS group compared with the non-p-aHUS group (mean \pm SD $0.5 \pm 1.4$ months and $4.5 \pm 40.6$ months, respectively). The proportion of women with a family history of
aHUS was similar across treatment subgroups, ranging from approximately $11.1 \%$ to $14.6 \%$ (Table 1 ). In $50 / 51$ (98.0\%) patients with p-aHUS, the index pregnancy was their first pregnancy, and no pregnancies were reported after initial TMA complications. In women with non-p-aHUS, $33 / 395$ (8.4\%) had pregnancies prior to enrollment or while enrolled, of which approximately half (18/33) were prior to initial TMA complications. Just over half of women with p-aHUS experienced initial TMA manifestations/complications during pregnancy (54.9\% during pregnancy and $45.1 \%$ postpartum). The trimester in which initial TMA complications occurred was only recorded for 28/51 women (Table 1).

Overall, 12/51 (23.5\%) women with p-aHUS had a kidney transplant(s), all after their index pregnancy. Of the women with non-p-aHUS, 136/395 (34.4\%) underwent a kidney transplant: $34(8.6 \%)$ prior to aHUS diagnosis and 113 (28.6\%) after diagnosis (not mutually exclusive). Kidney transplantations after index pregnancy or aHUS diagnosis were more common in women who did not receive eculizumab treatment compared with those who were treated with eculizumab (10/24 [41.7\%] vs $2 / 27$ [7.4\%] in women with p-aHUS and 98/198 [49.5\%] vs 15/187 [8.0\%] in those with non-p-aHUS, respectively) (Table 1).

The proportion of women undergoing dialysis at the time of initial TMA manifestation was comparable across all groups (Table 1). The proportion of women with extrarenal manifestations (cardiovascular, pulmonary, central nervous system-related, or gastrointestinal) at the time of initial TMA was similar for women with p-aHUS and nonp-aHUS, and in both groups this baseline proportion was higher in eculizumab-treated women compared with those not treated with eculizumab (Table 1).

Table 2 Summary of complement genetic profiles of women with p-aHUS and non-p-aHUS

\begin{tabular}{|c|c|c|c|c|c|c|}
\hline & \multicolumn{3}{|c|}{ Women with p-aHUS $(n=51)$} & \multicolumn{3}{|c|}{ Women with non-p-aHUS $(n=397)^{\mathrm{a}}$} \\
\hline & $\begin{array}{l}\text { Eculizumab treated } \\
(n=27)\end{array}$ & $\begin{array}{l}\text { Not treated } \\
\text { with eculi- } \\
\text { zumab } \\
(n=24)\end{array}$ & $\begin{array}{l}\text { All patients } \\
(n=51)\end{array}$ & $\begin{array}{l}\text { Eculizumab treated } \\
(n=187)\end{array}$ & $\begin{array}{l}\text { Not treated } \\
\text { with eculi- } \\
\text { zumab } \\
(n=197)\end{array}$ & $\begin{array}{l}\text { All patients } \\
(n=397)\end{array}$ \\
\hline Any pathogenic variant, $n(\%)$ & $10(37.0)$ & $13(54.2)$ & $23(45.1)$ & $68(36.4)$ & $89(44.9)$ & $159(40.1)$ \\
\hline Anti-CFH antibody positive, $n(\%)^{\mathrm{a}}$ & $1(3.7)$ & $2(8.3)$ & $3(5.9)$ & $16(8.6)$ & $17(8.6)$ & $33(8.3)$ \\
\hline $\begin{array}{l}\text { Any pathogenic variant or anti-CFH } \\
\text { antibody positive, } n(\%)\end{array}$ & $10(37.0)$ & $13(54.2)$ & $23(45.1)$ & $75(40.1)$ & $93(47.0)$ & $170(42.8)$ \\
\hline $\begin{array}{l}\text { Tested for } \geq 5 \text { pathogenic variants, no } \\
\text { mutation identified, } n(\%)\end{array}$ & $11(40.7)$ & $3(12.5)$ & $14(27.5)$ & $61(32.6)$ & $51(25.8)$ & $119(30.0)$ \\
\hline $\begin{array}{l}\text { Tested for }<5 \text { pathogenic variants, no } \\
\text { mutation identified, } n(\%)\end{array}$ & $1(3.7)$ & $2(8.3)$ & $3(5.9)$ & $8(4.3)$ & $14(7.1)$ & $23(5.8)$ \\
\hline
\end{tabular}

aHUS atypical hemolytic uremic syndrome, $C N S$ central nervous system, $C F H$ complement factor $\mathrm{H}, p$ - $a H U S$ pregnancy-triggered aHUS

${ }^{a}$ Includes 10 women with missing information on initial eculizumab dose and 2 women with unknown eculizumab treatment status 


\section{Treatment characteristics}

Twenty-seven (52.9\%) women with p-aHUS and 187 (47.3\%) women with non-p-aHUS received eculizumab treatment. The mean \pm SD duration of eculizumab treatment was $1.78 \pm 1.76$ years and $2.87 \pm 2.35$ years, and the mean \pm SD time from initial TMA to treatment initiation was $0.07 \pm 0.13$ years and $1.64 \pm 4.78$ years in women with p-aHUS and non-p-aHUS, respectively.

Overall, the proportion of women who had undergone PE/ $\mathrm{PI}$ at any time was similar for those with p-aHUS and nonp-aHUS (78.4\% and 70.9\%, respectively, Table 1); for those treated with eculizumab, 22/27 (81.5\%) women with p-aHUS and 125/187 (66.8\%) women with non-p-aHUS had undergone PE/PI prior to eculizumab. The duration of PE/PI treatment was longer for women with non-p-aHUS (mean \pm SD duration $16.7 \pm 19.9$ days and $129.8 \pm 531.8$ days for those with p-aHUS and non-p-aHUS, respectively). The duration of PE/PI was shorter for women treated with eculizumab compared with those not treated with eculizumab in both aHUS groups $(13.2 \pm 16.1$ days vs $20.9 \pm 23.4$ days in those with p-aHUS and $41.2 \pm 154.5$ days vs $211.8 \pm 713.1$ days in those with non-p-aHUS). These findings were irrespective of whether PE/PI treatment was undergone prior to or after eculizumab treatment.

\section{Complement genetics}

The prevalence of pathogenic variants in complement genes and anti-CFH antibodies was compared for both aHUS groups (Table 2). The complement genes tested were: complement $\mathrm{C} 3$; complement factors $\mathrm{H}$, I, and B; complement CD46 (membrane cofactor protein); and thrombomodulin. The complement genetics and antibody status of women with p-aHUS and non-p-aHUS were similar; the proportion of those with pathogenic variant(s) in complement genes and/or anti-CFH antibody was $45.1 \%$ (23/51) and $42.8 \%$ (170/397), respectively.
Fig. 2 Probability of renal survival after initial TMA complications with eculizumab treatment versus no eculizumab treatment for a women with p-aHUS and $\mathbf{b}$ women with non-p-aHUS, analyzed using the Kaplan-Meier method. ${ }^{a}$ Adjusted HR covariates: plasma exchange/plasma infusion, dialysis, and the presence of at least one complement gene mutation and/or anti-CFH antibody positive status, at the time of initial TMA. aHUS atypical hemolytic uremic syndrome, ESRD endstage renal disease, $H R$ hazard ratio, $p$ - $a H U S$ pregnancy-triggered aHUS, TMA thrombotic microangiopathy

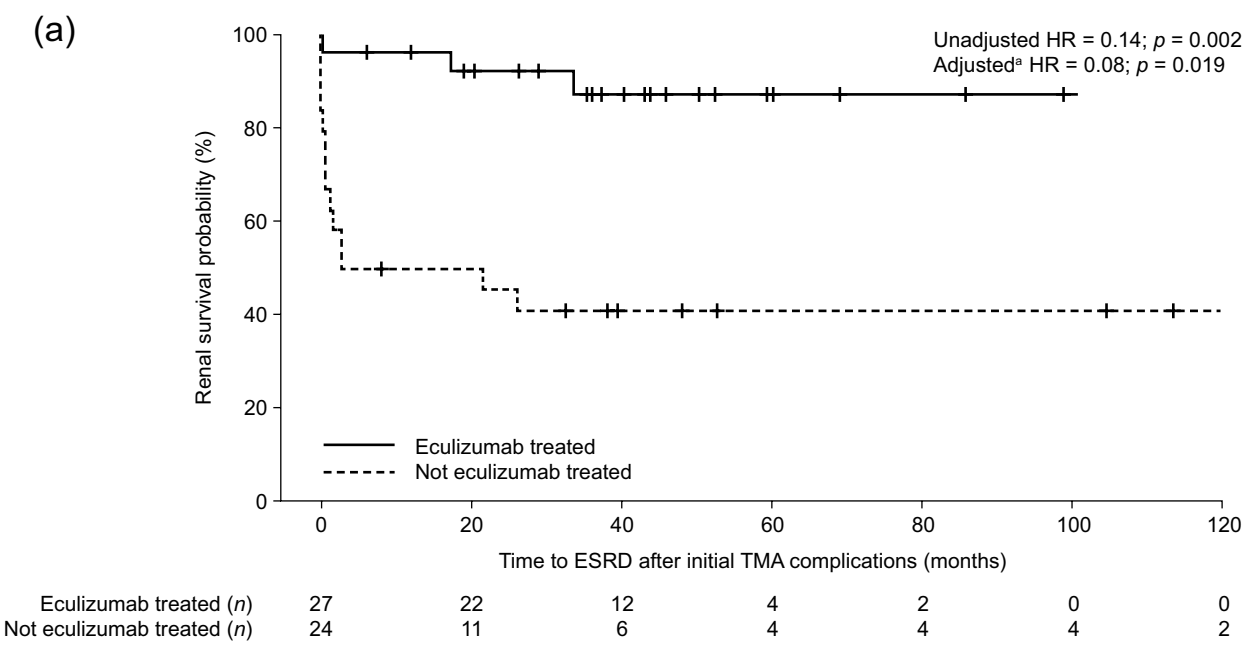

(b)

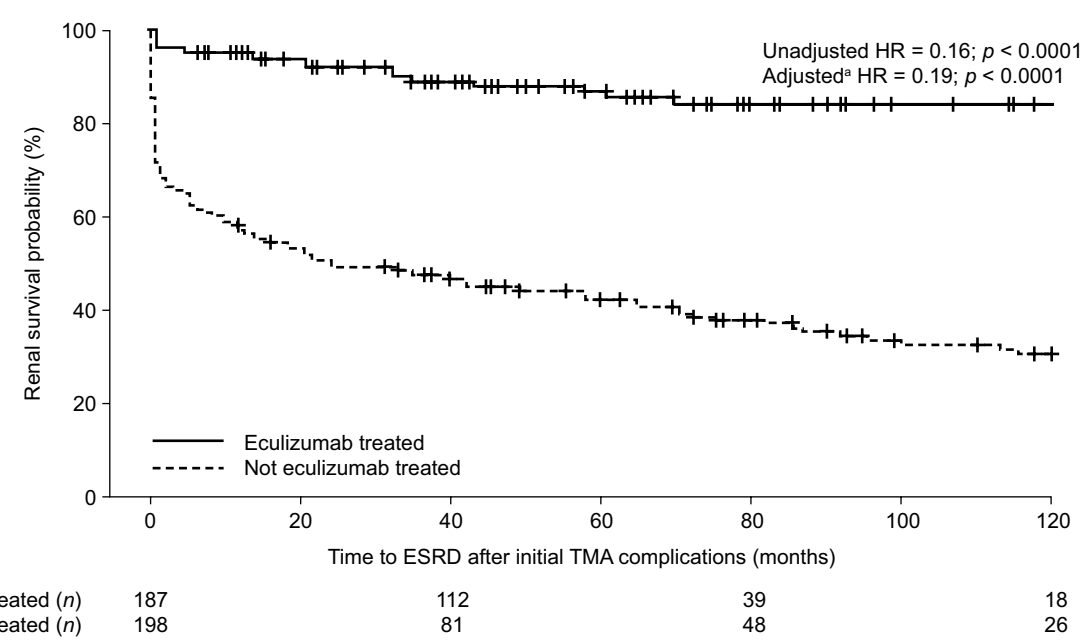




\section{Outcomes}

The mean \pm SD follow-up period was $3.73 \pm 2.01$ years and $4.00 \pm 1.97$ years for women with $\mathrm{p}$-aHUS and non-p-aHUS, respectively. At the last follow-up, the numbers of women with p-aHUS and non-p-aHUS receiving eculizumab treatment were 18 (35.3\%) and 179 (45.1\%), respectively.

Renal outcomes were evaluated by measuring the time from initial TMA manifestation to ESRD and the change in estimated glomerular filtration rate (eGFR). Kaplan-Meier curves were generated to compare the time from initial TMA manifestation to ESRD with and without eculizumab treatment (Fig. 2). The risk of ESRD was significantly higher for women not treated with eculizumab, compared with eculizumab-treated women, in both aHUS groups: the unadjusted HR was 0.14 (95\% confidence interval $[\mathrm{CI}] 0.04,0.47 ; p=0.002)$ in the $\mathrm{p}$-aHUS group and 0.16 (95\% CI $0.11,0.24 ; p<0.0001)$ in the non-p-aHUS group. The HR adjusted for dialysis, PE/PI treatments, and at least one complement gene mutation and/or anti-CFH antibody positive status, at the time of initial TMA was 0.08 (95\% CI $0.01,0.65 ; p=0.019)$ and 0.19 (95\% CI 0.10, 0.36; $p<0.0001$ ), respectively. In both aHUS groups, the eGFR improved after eculizumab treatment, with a mean \pm SD increase relative to baseline of $56.2 \pm 39.8$ and $40.9 \pm 32.1 \mathrm{~mL} / \mathrm{min} / 1.73 \mathrm{~m}^{2}$, for patients with p-aHUS and non-p-aHUS, respectively.

The proportion of women with reported new onset cardiovascular, central nervous system, or gastrointestinal manifestations was comparable between the aHUS groups and ranged from $17.1 \%$ to $25.9 \%$ across all treatment groups. In women with p-aHUS, pulmonary manifestations were reported for $25.9 \%$ and $0 \%$ of those treated and not treated with eculizumab, respectively, compared with approximately $8 \%$ of women with non-p-aHUS (both treated and not treated with eculizumab).

Pregnancy complications were reported for women with p-aHUS. Overall, 54.9\% had pre-eclampsia and 33.3\% HELLP syndrome, with no notable differences between women treated with eculizumab and those not treated with eculizumab. Cesarean sections were performed for $29.6 \%$ and $20.8 \%$ of women treated and not treated with eculizumab, respectively.

\section{Discussion}

Previous studies of $\mathrm{p}$-aHUS have helped to characterize this subset of the aHUS population; however, direct comparisons with aHUS not associated with identifiable triggers have not been feasible [25]. The current analysis compared characteristics and renal outcomes in women with p-aHUS to those of childbearing age with aHUS but no associated triggers
(non-p-aHUS), based on data retrieved from the Global aHUS Registry as a source of a single, large cohort. There were no eligible women with p-aHUS younger than 18 years in the Global aHUS Registry, therefore, for the purposes of this study, the inclusion criteria for the comparator group of 'women of childbearing age' specified a minimum age of 18 years. Our results showed that both groups were similar in several demographic and clinical characteristics, as well as in their response to eculizumab.

In this study, $43 \%$ of women in the p-aHUS group had pathogenic variant(s) in complement genes or anti-CFH antibodies and the proportion was similar in the non-paHUS comparator group (45\%). These percentages are within the range of reported rates of complement genetic abnormalities in patients with aHUS (45-70\%) [5, 6, 26, 27]. The proportion of women with a family history of aHUS was also similar in both groups.

The proportion of women on dialysis at the time of initial TMA manifestations was $14 \%$ and $11 \%$ for the p-aHUS and non-p-aHUS groups, respectively, indicating a similarity in renal function. Furthermore, the rate of kidney transplants for women treated versus not treated with eculizumab was similar within both aHUS groups (higher for those not treated with eculizumab), indicating a similarity in renal prognosis in women with p-aHUS and women with aHUS not triggered by pregnancy.

Extra-renal manifestations are common in patients with aHUS and have been hypothesized to be related to acute and chronic complement activation and dysregulation [28]. In an assessment of data from the Global aHUS Registry by Schaefer et al., extra-renal manifestations were reported for $19-38 \%$ of patients within the initial presenting phase, prior to eculizumab treatment, with gastrointestinal manifestations being the most prevalent [26]. The similar frequencies of extra-renal manifestations in the aHUS groups in this study again suggest the same disease presentation. Extra-renal manifestations at baseline were more prevalent in women later treated with eculizumab compared with those not treated with eculizumab in both aHUS groups. It is possible that physicians consider these symptoms a risk factor for TMA and hence these women are more likely to be diagnosed and treated; this may explain why a higher prevalence of extra-renal manifestations in women treated with eculizumab was found in this study.

Treatment with eculizumab significantly reduced the risk of ESRD in women with p-aHUS and non-p-aHUS, compared with no eculizumab treatment. It is acknowledged that, owing to the non-interventional nature of this study, comparison of outcomes for women treated and not treated with eculizumab may be subject to bias, as treatment decisions by physicians were not protocolized and could be influenced by a number of presenting factors. Cox regression modeling of the data for treated versus not treated groups was therefore 
adjusted for covariates deemed likely to influence treatment decisions (namely dialysis and/or PE/PI treatment at the time of initial TMA, and complement gene mutations and/or anti$\mathrm{CFH}$ antibodies). A reduced risk of ESRD in women treated with eculizumab, compared with those not treated with eculizumab, was observed even when the data were adjusted for these covariates (for both aHUS groups). Improved renal outcomes for women in both aHUS groups treated with eculizumab were also indicated by an increase in mean eGFR from baseline. Similarity in response of complement C5 inhibition indicates similar disease pathophysiology in p-aHUS and aHUS not associated with identifiable triggers.

In women with p-aHUS, $98 \%$ of TMAs were reported during first pregnancy. This is a greater proportion than has been reported in the literature (40-70\%) [29]; however, reporting bias of pregnancy history cannot be ruled out because previous pregnancies with no complications may be under-reported. Just over half of initial TMA manifestations/complications occurred during pregnancy, with the rest occurring within 60 days postpartum. This is in contrast to reports in the literature in which p-aHUS incidence is reported to be higher postpartum [10, 11, 29]. Diagnosis of p-aHUS is often delayed owing to the overlapping clinical and laboratory features of $\mathrm{p}$-aHUS with other known pregnancy complications such as pre-eclampsia and HELLP syndrome; therefore, the proportion of cases occurring during pregnancy may be under-estimated in the literature [30, 31]. In the current study, a high rate of pre-eclampsia (55\%) and HELLP syndrome (33\%) was also reported, with many women reporting both (20\%).

Approximately half of the women in this study were not treated with eculizumab, many of whom had received a diagnosis prior to the availability of this complement C5 inhibitor in 2011 (during the time period 1985-2010, initial TMA manifestations were reported for $19.6 \%$ and $36.2 \%$ of women in the p-a-HUS and non-p-aHUS groups, respectively). The mean time from initial TMA manifestation to aHUS diagnosis was longer in women with non-p-aHUS than in those with p-aHUS, and in women not treated with eculizumab than in those treated with eculizumab. This may in part be explained by the higher proportion of women in the non-p-aHUS and non-eculizumab-treated groups who experienced initial TMA manifestations during an earlier timeframe, when aHUS was less widely recognized. The earlier date of initial TMA manifestations may also explain the longer mean time from initial TMA manifestation to treatment initiation in women with non-p-aHUS. Pregnancy has been increasingly recognized as a trigger for aHUS involving complement over-activation, which may be the reason for the shorter length of time from initial TMA to aHUS diagnosis and initiation of eculizumab treatment in the p-aHUS group, compared with the non-p-aHUS group [11, 29]. The duration of PE/PI treatment was shorter in the p-aHUS group than in the non-p-aHUS group and it was shorter for women treated with eculizumab than those not treated with eculizumab, likely owing to the discontinuation of PE/PI upon the initiation of eculizumab as standard of care treatment.

The findings from this study support the classification of p-aHUS as a complement-mediated TMA, based on clinical characteristics, complement genetics, and response to eculizumab treatment. It is acknowledged that there are some limitations to this study, owing to its observational design and the real-world setting of the Global aHUS Registry, including missing data for some women, the fact that not all women treated with eculizumab were on the same dosing regimen (and some had an unreported dose level), and potential variation in interpretation of disease characteristics.

\section{Conclusions}

Findings from this large collection of data from a single, real-world, global cohort confirm that pregnancy-triggered aHUS is comparable to aHUS with no identified trigger. Our results indicate that pregnancy-triggered aHUS is not only a disease of the postpartum period, and that presumed pregnancy-associated TMAs may well be aHUS. The similarities in demographics, clinical characteristics, complement genetics, disease progression, and response to eculizumab between women in both groups confirm that pregnancytriggered aHUS can be considered a complement-mediated TMA.

Supplementary Information The online version contains supplementary material available at https://doi.org/10.1007/s40620-021-01025-x.

Acknowledgements The sponsor and investigators thank the patients and their families for their participation in, and support for, this clinical study. The authors would also like to thank all the Global aHUS Registry investigators who have contributed data, Scientific Advisory Board members of the Global aHUS Registry: Christoph Licht, Véronique Frémeaux-Bacchi, Gema Ariceta, Larry Greenbaum, Sally Johnson, Franz Schaefer, Jeff Schmidt, Margriet Eygenraam and Christoph Gasteyger; and National Coordinators of the Global aHUS Registry: Miquel Blasco (Spain), Donata Cresseri (Italy), Galina Generolova (Russia), Nicholas Webb (United Kingdom), Patricia Hirt-Minkowski (Switzerland), Natalya Lvovna Kozlovskaya (Russia), Danny Landau (Israel), Anne-Laure Lapeyraque (Canada), Chantal Loirat (France), Christoph Mache (Austria), Michal Malina (Czech Republic), Leena Martola (Finland), Annick Massart (Belgium), Eric Rondeau (France), and Lisa Sartz (Sweden). The authors would like to acknowledge Sally McTaggart, PhD, Oxford Pharmagenesis for providing editorial and medical writing support with funding from Alexion Pharmaceuticals, Inc. and Radha Narayan, PhD, Alexion Pharmaceuticals, Inc. for critical review of the manuscript.

Funding Open Access funding provided by The University of Lausanne, Lausanne, Switzerland. This analysis was funded by Alexion Pharmaceuticals, Inc. Alexion Pharmaceuticals, Inc. was responsible for the collection, management, and analysis of information contained in the Global aHUS Registry. Alexion Pharmaceuticals, Inc. contributed to 
data interpretation, preparation, review, and approval of the manuscript for submission. All authors had full access to all the data in the study and had final responsibility for the decision to submit for publication.

Availability of data and materials Alexion will consider requests for disclosure of clinical study participant-level data provided that participant privacy is assured through methods like data de-identification, pseudonymization, or anonymization (as required by applicable law), and if such disclosure was included in the relevant study Informed Consent form or similar documentation. Qualified academic investigators may request participant-level clinical data and supporting documents (statistical analysis plan and protocol) pertaining to Alexion-sponsored studies. Further details regarding data availability and instructions for requesting information are available in the Alexion Clinical Trials Disclosure and Transparency Policy at http://alexion.com/research-devel opment. Link to Data Request Form (https://alexion.com/contact-alexi on/medical-information).

\section{Declarations}

Conflict of interest F Fakhouri has received fees for expertise, consultancy, and scientific symposia from Alexion Pharmaceuticals, Inc. M Scully has received speaker fees and is on an advisory board for Alexion Pharmaceuticals, Inc. G Ardissino has received speaker fees and is on an advisory board for Alexion Pharmaceuticals, Inc. I Al-Dakkak is an employee of, and may own stocks/options in Alexion Pharmaceuticals, Inc. B Miller was an employee of Alexion Pharmaceuticals, Inc. at the time of this study. E Rondeau has received fees for expertise, consultancy, and scientific symposia from Alexion Pharmaceuticals, Inc.

Consent to participate A written informed consent was obtained from each patient prior to participation in the study. The Sponsor or its designee could provide an informed consent template to the sites, if required. If the site made any institution-specific modifications, the Sponsor or its designee could review the consent prior to IRB/EC submission. The Investigator or the Sponsor would then submit the approved, revised consent to the appropriate IRB/EC for review and approval prior to the start of the study. If the consent form was revised during the course of the study, all active participating patients to whom the revision may have had an impact must have signed the revised form. Before recruitment and enrollment, each patient was given a full explanation of the study and was allowed time to read the approved informed consent form. Once the Investigator was assured that the individual understood the implications of participating in the study, the patient was asked to give consent to participate in the study by signing the informed consent form. The Investigator provided a copy of the signed informed consent to the patient. The original form was maintained in the study files at the site.

Consent for publication The sponsors of this study (Alexion Pharmaceuticals, Inc.) have provided consent for publication.

Ethical approval This was a multicenter study comprising many different sites of enrollment. Federal, provincial, and local regulations and International Conference on Harmonization (ICH) guidelines, if relevant, required that approval was obtained from an Ethics Committee (EC)/Independent review Board (IRB) prior to participation of patients in research studies. Where required and prior to the study onset, the EC/IRB must have approved the protocol, Informed Consent, advertisements to be used for patient recruitment, and any other written information regarding this study to be provided to the patient or the patient's parents/legal guardian. The sites maintained and made available for review by the Sponsor or its designee documentation of all EC/ IRB approvals and of the EC/IRB compliance with ICH Guidance E6:
Good Clinical Practice, if relevant. All EC/IRB approvals were signed by the EC/IRB Chairman or designee and identified the EC/IRB name and address, the clinical protocol by title and/or protocol number, and the date approval and/or favorable opinion was granted. The Investigator conducted all aspects of this study in accordance with all national, provincial, and local laws of the pertinent regulatory authorities.

Open Access This article is licensed under a Creative Commons Attribution 4.0 International License, which permits use, sharing, adaptation, distribution and reproduction in any medium or format, as long as you give appropriate credit to the original author(s) and the source, provide a link to the Creative Commons licence, and indicate if changes were made. The images or other third party material in this article are included in the article's Creative Commons licence, unless indicated otherwise in a credit line to the material. If material is not included in the article's Creative Commons licence and your intended use is not permitted by statutory regulation or exceeds the permitted use, you will need to obtain permission directly from the copyright holder. To view a copy of this licence, visit http://creativecommons.org/licenses/by/4.0/.

\section{References}

1. George JN, Nester CM (2014) Syndromes of thrombotic microangiopathy. NEJM 371(7):654-666. https://doi.org/10.1056/NEJMr a1312353

2. Campistol JM, Arias M, Ariceta G, Blasco M, Espinosa L, Espinosa M, Grinyó JM, Macía M, Mendizábal S, Praga M, Román E, Torra R, Valdés F, Vilalta R, Rodríguez de Córdoba S (2015) An update for atypical haemolytic uraemic syndrome: diagnosis and treatment. A consensus document. Nefrologia 35(5):421-447. https://doi.org/10.1016/j.nefro.2015.07.005

3. Fakhouri F, Zuber J, Frémeaux-Bacchi V, Loirat C (2017) Haemolytic uraemic syndrome. Lancet 390(10095):681-696. https://doi. org/10.1016/S0140-6736(17)30062-4

4. Sellier-Leclerc AL, Fremeaux-Bacchi V, Dragon-Durey MA, Macher MA, Niaudet P, Guest G, Boudailliez B, Bouissou F, Deschenes G, Gie S, Tsimaratos M, Fischbach M, Morin D, Nivet H, Alberti C, Loirat C (2007) Differential impact of complement mutations on clinical characteristics in atypical hemolytic uremic syndrome. J Am Soc Nephrol 18(8):2392-2400. https://doi.org/ 10.1681/asn.2006080811

5. Fremeaux-Bacchi V, Fakhouri F, Garnier A, Bienaimé F, DragonDurey MA, Ngo S, Moulin B, Servais A, Provot F, Rostaing L, Burtey S, Niaudet P, Deschênes G, Lebranchu Y, Zuber J, Loirat C (2013) Genetics and outcome of atypical hemolytic uremic syndrome: a nationwide French series comparing children and adults. Clin J Am Soc Nephrol 8(4):554-562. https://doi.org/10.2215/cjn. 04760512

6. Noris M, Caprioli J, Bresin E, Mossali C, Pianetti G, Gamba S, Daina E, Fenili C, Castelletti F, Sorosina A, Piras R, Donadelli R, Maranta R, van der Meer I, Conway EM, Zipfel PF, Goodship TH, Remuzzi G (2010) Relative role of genetic complement abnormalities in sporadic and familial aHUS and their impact on clinical phenotype. Clin J Am Soc Nephrol 5(10):1844-1859. https://doi.org/10.2215/cjn.02210310

7. Nester CM, Barbour T, de Cordoba SR, Dragon-Durey MA, Fremeaux-Bacchi V, Goodship TH, Kavanagh D, Noris M, Pickering M, Sanchez-Corral P, Skerka C, Zipfel P, Smith RJ (2015) Atypical aHUS: state of the art. Mol Immunol 67(1):31-42. https://doi. org/10.1016/j.molimm.2015.03.246

8. Goodship TH, Cook HT, Fakhouri F, Fervenza FC, FrémeauxBacchi V, Kavanagh D, Nester CM, Noris M, Pickering MC, 
Rodríguez de Córdoba S, Roumenina LT, Sethi S, Smith RJ (2017) Atypical hemolytic uremic syndrome and C3 glomerulopathy: conclusions from a "Kidney Disease: Improving Global Outcomes" (KDIGO) Controversies Conference. Kidney Int 91(3):539-551. https://doi.org/10.1016/j.kint.2016.10.005

9. Bayer G, von Tokarski F, Thoreau B, Bauvois A, Barbet C, Cloarec S, Mérieau E, Lachot S, Garot D, Bernard L, Gyan E, Perrotin F, Pouplard C, Maillot F, Gatault P, Sautenet B, Rusch E, Buchler M, Vigneau C, Fakhouri F, Halimi J-M (2019) Etiology and outcomes of thrombotic microangiopathies. Clin J Am Soc Nephrol 14(4):557. https://doi.org/10.2215/CJN.11470918

10. Fakhouri F, Roumenina L, Provot F, Sallée M, Caillard S, Couzi L, Essig M, Ribes D, Dragon-Durey M-A, Bridoux F, Rondeau E, Frémeaux-Bacchi V (2010) Pregnancy-associated hemolytic uremic syndrome revisited in the era of complement gene mutations. J Am Soc Nephrol JASN 21(5):859-867. https://doi.org/10. 1681/ASN.2009070706

11. Bruel A, Kavanagh D, Noris M, Delmas Y, Wong EKS, Bresin E, Provôt F, Brocklebank V, Mele C, Remuzzi G, Loirat C, Frémeaux-Bacchi V, Fakhouri F (2017) Hemolytic uremic syndrome in pregnancy and postpartum. Clin J Am Soc Nephrol 12(8):1237-1247. https://doi.org/10.2215/cjn.00280117

12. European Medicines Agency Ultomiris (ravulizumab). https:// www.ema.europa.eu/en/medicines/human/EPAR/ultomiris. Accessed Nov 2020

13. European Medicines Agency Soliris (eculizumab). https://www. ema.europa.eu/en/documents/product-information/soliris-eparproduct-information_en.pdf. Accessed Nov 2020

14. US Food and Drug Administration Soliris (eculizumab). https:// www.accessdata.fda.gov/drugsatfda_docs/label/2019/125166s431 lbl.pdf. Accessed Nov 2020

15. US Food and Drug Administration Ultomiris (ravuliazumabcwvz). https://www.accessdata.fda.gov/drugsatfda_docs/label/ 2019/761108s001lbl.pdf. Accessed Nov 2020

16. Legendre CM, Licht C, Muus P, Greenbaum LA, Babu S, Bedrosian C, Bingham C, Cohen DJ, Delmas Y, Douglas K, Eitner F, Feldkamp T, Fouque D, Furman RR, Gaber O, Herthelius M, Hourmant M, Karpman D, Lebranchu Y, Mariat C, Menne J, Moulin B, Nurnberger J, Ogawa M, Remuzzi G, Richard T, Sberro-Soussan R, Severino B, Sheerin NS, Trivelli A, Zimmerhackl LB, Goodship T, Loirat C (2013) Terminal complement inhibitor eculizumab in atypical hemolytic-uremic syndrome. $\mathrm{N}$ Engl J Med 368(23):2169-2181. https://doi.org/10.1056/NEJMo a1208981

17. Rondeau E, Cataland SR, Al-Dakkak I, Miller B, Webb NJA, Landau D (2019) Eculizumab safety: five-year experience from the global atypical hemolytic uremic syndrome registry. Kidney Int Rep 4(11):1568-1576. https://doi.org/10.1016/j.ekir.2019.07. 016

18. Siedlecki AM, Isbel N, Vande Walle J, James Eggleston J, Cohen DJ, Global aHUS Registry (2018) Eculizumab use for kidney transplantation in patients with a diagnosis of atypical hemolytic uremic syndrome. Kidney Int Rep 4(3):434-446. https://doi.org/ 10.1016/j.ekir.2018.11.010

19. Zuber J, Frimat M, Caillard S, Kamar N, Gatault P, Petitprez F, Couzi L, Jourde-Chiche N, Chatelet V, Gaisne R, Bertrand D, Bamoulid J, Louis M, Sberro Soussan R, Navarro D, Westeel PF, Frimat L, Colosio C, Thierry A, Rivalan J, Albano L, Arzouk N, Cornec-Le Gall E, Claisse G, Elias M, El Karoui K, Chauvet S, Coindre JP, Rerolle JP, Tricot L, Sayegh J, Garrouste C, Charasse C, Delmas Y, Massy Z, Hourmant M, Servais A, Loirat C, Fakhouri F, Pouteil-Noble C, Peraldi MN, Legendre C, Rondeau E, Le Quintrec M, Frémeaux-Bacchi V (2019) Use of highly individualized complement blockade has revolutionized clinical outcomes after kidney transplantation and renal epidemiology of atypical hemolytic uremic syndrome. J Am Soc Nephrol 30(12):2449_ 2463. https://doi.org/10.1681/asn.2019040331

20. Licht C, Greenbaum LA, Muus P, Babu S, Bedrosian CL, Cohen DJ, Delmas Y, Douglas K, Furman RR, Gaber OA, Goodship T, Herthelius M, Hourmant M, Legendre CM, Remuzzi G, Sheerin N, Trivelli A, Loirat C (2015) Efficacy and safety of eculizumab in atypical hemolytic uremic syndrome from 2-year extensions of phase 2 studies. Kidney Int 87(5):1061-1073. https://doi.org/10. 1038/ki.2014.423

21. Greenbaum LA, Fila M, Ardissino G, Al-Akash SI, Evans J, Henning P, Lieberman KV, Maringhini S, Pape L, Rees L, van de Kar NCAJ, Vande Walle J, Ogawa M, Bedrosian CL, Licht C (2016) Eculizumab is a safe and effective treatment in pediatric patients with atypical hemolytic uremic syndrome. Kidney Int 89(3):701-711. https://doi.org/10.1016/j.kint.2015.11.026

22. Fakhouri F, Hourmant M, Campistol JM, Cataland SR, Espinosa M, Gaber AO, Menne J, Minetti EE, Provot F, Rondeau E, Ruggenenti P, Weekers LE, Ogawa M, Bedrosian CL, Legendre CM (2016) Terminal complement inhibitor eculizumab in adult patients with atypical hemolytic uremic syndrome: a single-arm, open-label trial. Am J Kidney Dis 68(1):84-93. https://doi.org/10. 1053/j.ajkd.2015.12.034

23. CinicalTrials.gov (2012) Atypical hemoloytic urermic syndrome (aHUS) registry (NCT01522183)

24. Licht C, Ardissino G, Ariceta G, Cohen D, Cole JA, Gasteyger C, Greenbaum LA, Johnson S, Ogawa M, Schaefer F, Vande Walle J, Frémeaux-Bacchi V (2015) The global aHUS registry: methodology and initial patient characteristics. BMC Nephrol 16:207-207. https://doi.org/10.1186/s12882-015-0195-1

25. Gupta M, Govindappagari S, Burwick RM (2020) Pregnancyassociated atypical hemolytic uremic syndrome: a systematic review. Obstet Gynecol 135(1):46-58

26. Schaefer F, Ardissino G, Ariceta G, Fakhouri F, Scully M, Isbel N, Lommele A, Kupelian V, Gasteyger C, Greenbaum LA, Johnson S, Ogawa M, Licht C, Vande Walle J, Fremeaux-Bacchi V (2018) Clinical and genetic predictors of atypical hemolytic uremic syndrome phenotype and outcome. Kidney Int 94(2):408-418. https:// doi.org/10.1016/j.kint.2018.02.029

27. Bu F, Zhang Y, Wang K, Borsa NG, Jones MB, Taylor AO, Takanami E, Meyer NC, Frees K, Thomas CP, Nester C, Smith RJH (2018) Genetic analysis of 400 patients refines understanding and implicates a new gene in atypical hemolytic uremic syndrome. $\mathrm{J}$ Am Soc Nephrol 29(12):2809-2819. https://doi.org/10.1681/asn. 2018070759

28. Hofer J, Rosales A, Fischer C, Giner T (2014) Extra-renal manifestations of complement-mediated thrombotic microangiopathies. Front Pediatr. https://doi.org/10.3389/fped.2014.00097

29. Huerta A, Arjona E, Portoles J, Lopez-Sanchez P, Rabasco C, Espinosa M, Cavero T, Blasco M, Cao M, Manrique J, CabelloChavez V, Suñer M, Heras M, Fulladosa X, Belmar L, Sempere A, Peralta C, Castillo L, Arnau A, Praga M, Rodriguez de Cordoba S (2018) A retrospective study of pregnancy-associated atypical hemolytic uremic syndrome. Kidney Int 93(2):450-459. https:// doi.org/10.1016/j.kint.2017.06.022

30. Shanmugalingam R, Hsu D, Makris A (2018) Pregnancy-induced atypical haemolytic uremic syndrome: a new era with eculizumab. Obstet Med 11(1):28-31. https://doi.org/10.1177/1753495x17 704563

31. Gupta M, Feinberg BB, Burwick RM (2018) Thrombotic microangiopathies of pregnancy: Differential diagnosis. Pregnancy Hypertens 12:29-34. https://doi.org/10.1016/j.preghy.2018.02. 007

Publisher's Note Springer Nature remains neutral with regard to jurisdictional claims in published maps and institutional affiliations. 